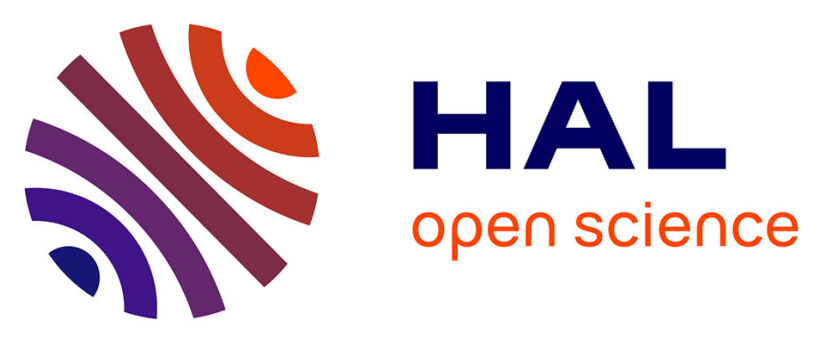

\title{
Advanced benchmark of the flow through a mixing vane grid - Large Eddy Simulation validation
}

Benjamin Farges, Marie-Charlotte Gauffre, Sofiane Benhamadouche, Pierre Badel, Vincent Faucher, Guillaume Ricciardi

\section{- To cite this version:}

Benjamin Farges, Marie-Charlotte Gauffre, Sofiane Benhamadouche, Pierre Badel, Vincent Faucher, et al. Advanced benchmark of the flow through a mixing vane grid - Large Eddy Simulation validation. Nuclear Engineering and Design, 2021, 381, pp.111335. 10.1016/j.nucengdes.2021.111335 . cea03409431

\section{HAL Id: cea-03409431 \\ https://hal-cea.archives-ouvertes.fr/cea-03409431}

Submitted on 29 Oct 2021

HAL is a multi-disciplinary open access archive for the deposit and dissemination of scientific research documents, whether they are published or not. The documents may come from teaching and research institutions in France or abroad, or from public or private research centers.
L'archive ouverte pluridisciplinaire HAL, est destinée au dépôt et à la diffusion de documents scientifiques de niveau recherche, publiés ou non, émanant des établissements d'enseignement et de recherche français ou étrangers, des laboratoires publics ou privés.

\section{(이) $\$$}

Distributed under a Creative Commons Attribution - NonCommercial - NoDerivatives $\mid 4.0$ 


\title{
Advanced benchmark of the flow through a mixing vane grid - Large Eddy Simulation validation
}

\author{
Farges Benjamin \\ Framatome \\ 10 rue Juliette Récamier, Lyon, FR-69006 \\ benjamin.farges@framatome.com

\section{Gauffre Marie-Charlotte} \\ $\mathrm{EDF}$ \\ 19 Rue Pierre Bourdeix, 69007 Lyon \\ marie-charlotte.gauffre@edf.fr

\section{Benhamadouche Sofiane} \\ EDF Lab \\ 6 quai Watier, Chatou, FR-78400 \\ sofiane.benhamadouche@edf.fr

\section{Badel Pierre \\ EDF Lab} \\ Boulevard Gaspard Monge, 91120 Palaiseau \\ Pierre-bernard.badel@edf.fr
}

\section{Faucher Vincent}

CEA, DES, IRESNE, Nuclear Technology Department, Center of Cadarache, Saint-Paul-lez-Durance, FR-13108 vincent.faucher@cea.fr

\section{Ricciardi Guillaume}

CEA, DES, IRESNE, Nuclear Technology Department, Center of Cadarache, Saint-Paul-lez-Durance, FR-13108 guillaume.ricciardi@cea.fr 


\title{
ABSTRACT
}

Identifying what causes fuel assembly vibrations downstream of Mixing Vane Grids (MVG) in Pressurized Water reactor (PWR) is of paramount importance for nuclear community to understand grid-to-rod fretting wear. Experiments, called CALIFS, were carried out by the Atomic Energy Commission (CEA) on a 5x5 MVG at a hydraulic Reynolds number of 66,000 , in order to measure the flow velocity and the pressure along the central rod. In parallel, a benchmark for Large Eddy Simulation (LES) was setup to compare the predictions of three different CFD codes: Star-CCM+,CCode_Saturne and TrioCFD to experimental measurements. The computational domain is representative of a span of CALIFS mockup, composed of a $5 \times 5$ rod bundle with a MVG. The three computations overall give very satisfactory results, independently from the mesh created and the modelling options selected. It seems to suggest that whatever the software used, this kind of calculations has reached a significant level of robustness and accuracy. Nonetheless, some discrepancies remain concerning the predictions of pressure standard deviation decay far downstream of the mixing vane grid.

5

(1)

\begin{abstract}
Pressurized Water Reactor fuel assembly, $5 \times 5$ mixing vane grid, CALIFS experiment, CFD benchmark,
\end{abstract} Large Eddy Simulation, pressure standard deviation.

\section{INTRODUCTION: INDUSTRIAL CHALLENGE AND PURPOSE OF THE PAPER}

Flow-induced vibrations (FIV) are a major research topic for nuclear reactor technology in general, and for the Pressurized Water Reactors in particular. Beyond the need to always prevent fluidelastic instability phenomena which could lead to rapid failures, it is also necessary to account for the long-time effects of the flow turbulence excitations. For instance, the grid-to-rod fretting wear is still a worldwide dominant fuel rod leaker mechanism [1] and its main cause has been identified as fuel rod vibration induced by the turbulent flow [2].

This topic is currently tackled through dedicated experiments. Carrying out the associated simulation is still a challenging field for Computational Fluid Dynamics (CFD) software due the stochastic and turbulenceinduced nature of the fluid loading applied to the structures at rod/grid level within a fuel assembly. Benhamadouche et al. [11] carried out wall-modelled LES of the flow through a $4 \times 4$ mixing vane grid at a Reynolds number of 40,000, in order to compute the pressure load. This latter has been used combined to a beam equation to predict the displacements obtained along a rod and the qualitative results corresponded 
34 to what is observed in reality (few microns). However, this computation cannot be considered as validated

35 and the methodology has to be confronted to experimental data. A dedicated Round Robin exercise to the

36 flow through Simple Support Grids and Mixing Vane Grids has been carried out by EPRI [12]. This

37 benchmark included heat transfer. Almost only RANS models have been employed in this benchmark and

38 the ability to capture pressure fluctuations has not been addressed.

39 Many recent attempts to simulate the fluid flow in a fuel assembly can be found in the literature. Bieder et

40 al. [16] showed that, downstream close to the mixing vane the turbulence is isotropic and anisotropic further

41 downstream. Chen et al. in [17] showed that simulation should count at least a 4 by 4 rod bundle to represent

42 a full bundle. The turbulent intensity generated by the mixing vanes is underestimated by standard k-epsilon

43 simulations [18], LES simulation perform better especially far from the grid [19]. The design of mixing van

44 has as strong influence on the turbulence [20], more specifically the inclination of the vanes increases the

45 turbulent intensity [21]. Spring and dimple have also an influence on the flow [22]. The MATiS-H

46 benchmark conducted by KAERI showed that simulation accounting for LES model with the finest mesh

47 does not guarantee the best results [23].

48 The purpose of the present article is to contribute to the definition of the state-of-the-art for industrial CFD 49 computation of single phase highly turbulent flow in rod bundles involving mixing grids. A particular focus 50 is dedicated to pressure fluctuations. The work involves cross-comparisons of predictions provided by three 51 different CFD solvers with various user-environment and objectives as well as various implemented 52 numerical methods and models for the case of interest, all evaluated with respect to a reference experiment 53 named CALIFS (see for instance [3] and [4]) described further in this introduction.

54 Such a benchmark, with results produced mobilizing a significantly high level of expert knowledge in the 55 use of each of considered software, is able to provide relevant insights regarding the capabilities of turbulent 56 CFD simulation going far beyond the proposed application and contribute to the definition of design 57 processes increasingly involving numerical results, with mandatory uncertainty assessment obtained from 58 detailed calculation at local scale.

\section{DESCRIPTION OF THE CALIFS 5X5 REFERENCE EXPERIMENT}

61 CALIFS 5x5, illustrated in Figure 1, is a water rig working within the ranges $0-400 \mathrm{~m} 3 / \mathrm{h}, 10^{\circ}-70^{\circ} \mathrm{C}, 0-10$ 62 bars. The length of the test section is about $2.5 \mathrm{~m}$. The flow cross section is a square of $184 \mathrm{~mm}$ side. A $5 \times 5$ 63 rods bundle, using rods of diameter $26.9 \mathrm{~mm}$, is placed within the test section using spacer-grids, with one 64 grid of interest with full optical access (see Figure 1-c and Figure 1-d). The hydraulic diameter (denoted $D_{h}$ 
65 in the following) of the bundle is $27.7 \mathrm{~mm}$ and is used as the reference length scale. The scale of the

66 experiment is higher than 1 is order to use appropriate sensors to measure the pressure along the rods.

67 The grids are made with $1.2 \mathrm{~mm}$ thick plates of stainless steel 304L. The height of the plates is $93 \mathrm{~mm}$ and 68 they are assembled perpendicularly to design a mesh with 25 cells. Within each cell, the rods are sustained 69 radially using dimples and springs-blades, representative of a realistic Mixing Vane Grid (MVG). The 70 dimples are made of TEFLON ${ }^{1}$ and the springs-blades are made with $1 \mathrm{~mm}$ thick blades of stainless steel $71301 \mathrm{~T} 4$.

72

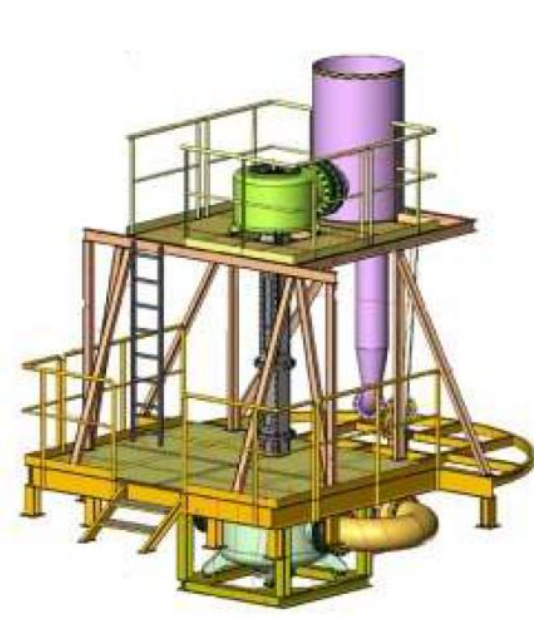

(a) General view of CALIFS $5 \times 5$ test rig

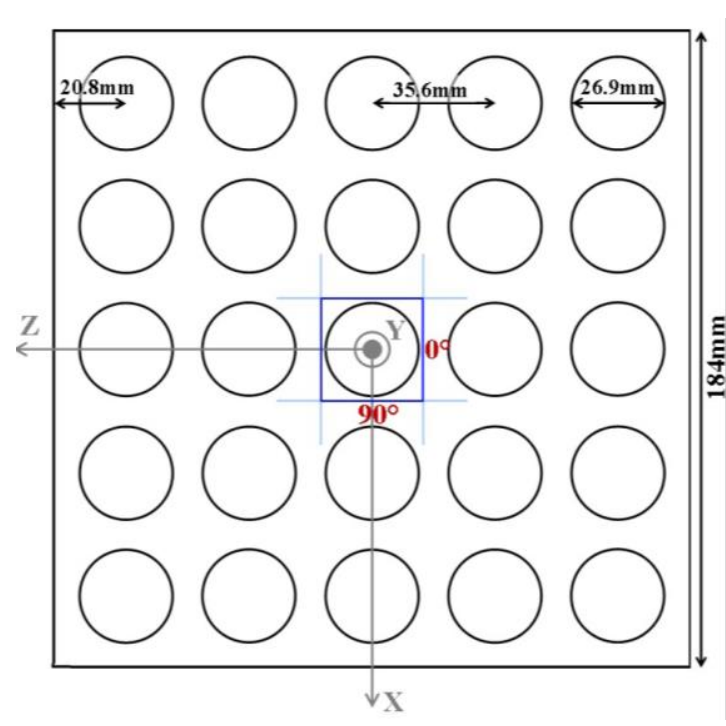

(b) Main dimensions and orientations

(c) View of the test section

\footnotetext{
${ }^{1}$ TEFLON is a registered trademark of E. I. du Pont de Nemours and Company or its affiliates.
} 

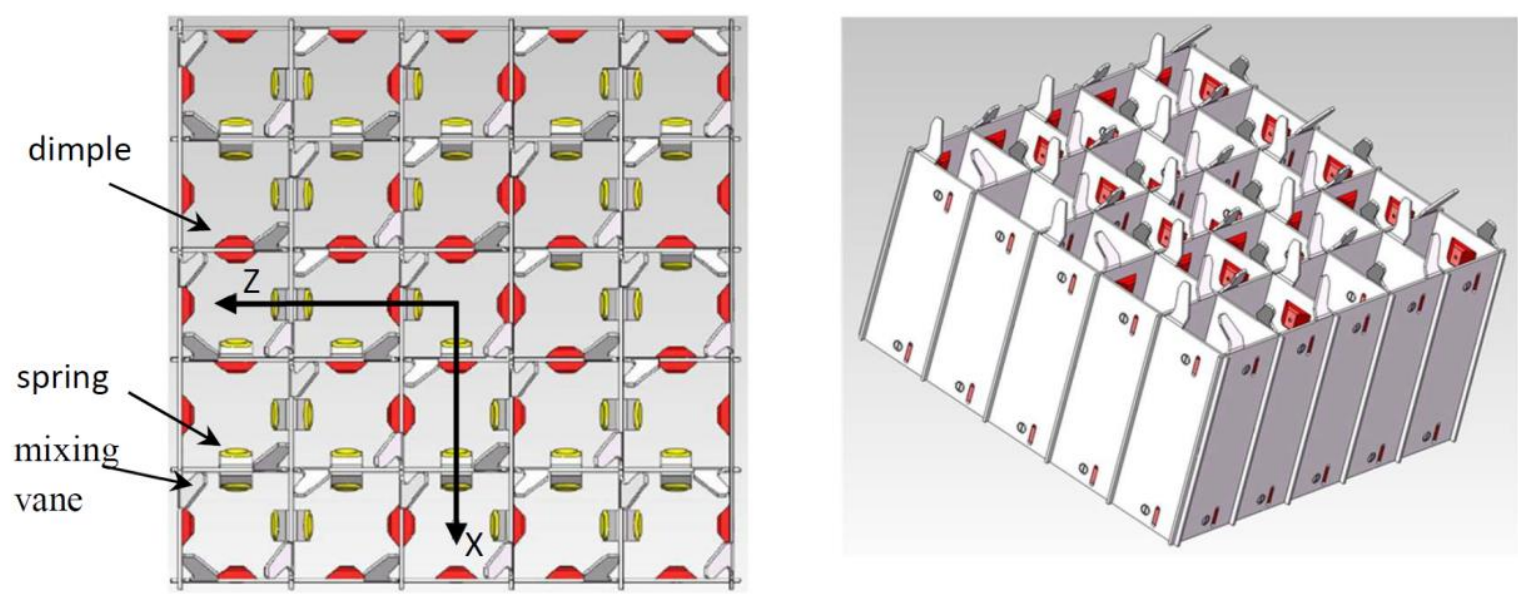

(d) View of the details of the mixing grid equipped with vanes

\section{Figure 1. Some details about the CALIFS 5x5 reference experiment}

74 The tests are performed for a flow rate velocity of $2.4 \mathrm{~m} \cdot \mathrm{s}^{-1}$ and a flow temperature of $20^{\circ} \mathrm{C}$, yielding a reference hydraulic Reynolds number of 66,000 , enough to significantly challenge the simulation results in the turbulent regime.

77 Global pressure drops along the bundle and unsteady local pressure measurements are implemented, the latter being obtained by instrumenting the central rod of the $5 \times 5$ rods bundle with a high-resolution piezoresistive sensor. The pressure distribution around the central rod circumference is obtained by turning the instrumented rod with an increment of $10^{\circ}$ over $360^{\circ}$. This azimuthal distribution is measured at various

81 longitudinal positions downstream of the grid of interest by translating the instrumented rod. The 82 longitudinal distances which are studied are $0.5 \mathrm{D}_{\mathrm{h}}, 1 \mathrm{D}_{\mathrm{h}}, 2 \mathrm{D}_{\mathrm{h}}, 3 \mathrm{D}_{\mathrm{h}}, 4 \mathrm{D}_{\mathrm{h}}, 5 \mathrm{D}_{\mathrm{h}}, 10 \mathrm{D}_{\mathrm{h}}, 15 \mathrm{D}_{\mathrm{h}}$ and $20 \mathrm{D}_{\mathrm{h}}$ 83 downstream of the mixing grid, respectively. Figure 2 shows an example extracted from [4] of the 84 experimental distribution of pressure standard deviation against which numerical results will be evaluated. 85 Only the red curves are considered in the present paper, the blue curves being obtained with a preliminary 86 configuration without mixing vanes.

87 Average velocity profiles in the tube bundle are also provided through Laser Doppler Velocimetry (LDV) 88 to serve also as experimental references for numerical results evaluation. 


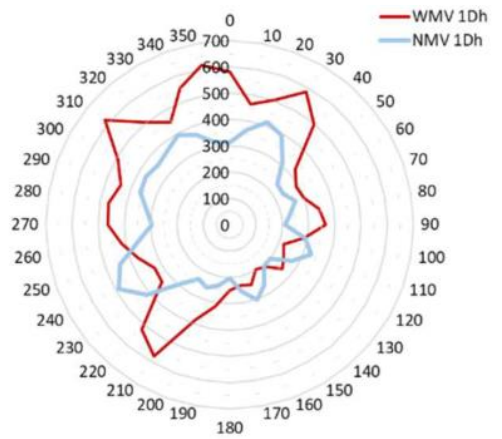

(a) $1 \mathrm{D}_{\mathrm{h}}$ downstream of the MVG

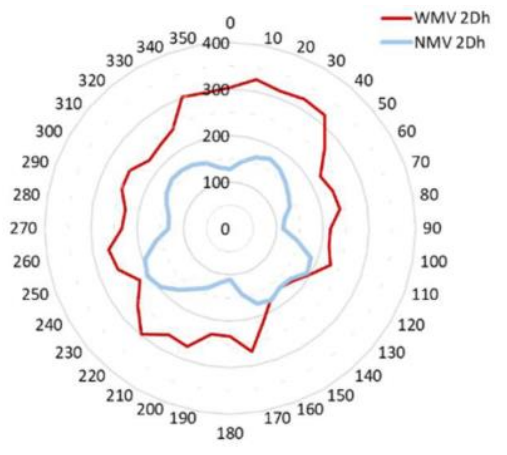

(b) $2 \mathrm{D}_{\mathrm{h}}$ downstream of the MVG

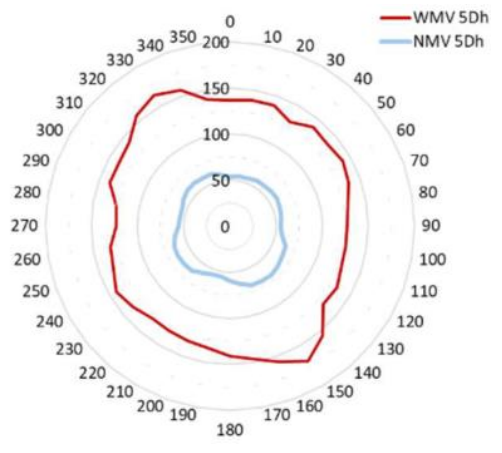

(c) $5 \mathrm{D}_{\mathrm{h}}$ downstream of the MVG

Figure 2. Pressure standard deviation obtained in CALIFS $5 \times 5$ experiment at different distances

from the mixing vane grid along the central rod (only the red curves have to be considered, the blue

\section{NUMERICAL MODELS}

96 Since the purpose of the benchmark was to challenge and compare complete numerical simulations

97 strategies for highly turbulent flow in a bundle configuration, numerical models mimicking CALIFS 5x5

98 experiment were built separately by Framatome, EDF and CEA using their usual solvers with their state of 99 the art of expertise. The selected CFD programs are given in Table 1. 


\begin{tabular}{|c|l||}
\hline Framatome & $\begin{array}{l}\text { Star-CCM+V11.2 } \\
\text { (https://www.plm.automation.siemens.com/global/fr/products/simcenter/Star- } \\
\text { CCM.html) } \\
\text { A fully industrial software solution from SIEMENS for design and } \\
\text { engineering, including advanced CFD and co-simulation. }{ }^{2}\end{array}$ \\
\hline EDF & $\begin{array}{l}\text { Code_Saturne V5.0 (https://www.code-saturne.org/) } \\
\text { A highly customizable open-source software for single phase laminar or } \\
\text { turbulent flows developed by EDF, for many kinds of applications in the } \\
\text { field of energy including in-core hydraulics for nuclear, external } \\
\text { atmospheric flows and flows interacting with rotors within steam turbine. }\end{array}$ \\
\hline CEA & $\begin{array}{l}\text { TrioCFD (http://triocfd.cea.fr) } \\
\text { A multi-purpose research open-source solution developed by CEA to } \\
\text { provide high-resolution solutions for complex flows with interfaces, } \\
\text { laminar or turbulent and designed for advanced multiphysical applications } \\
\text { and couplings. }\end{array}$ \\
\hline
\end{tabular}

Table 1. Selected software for Framatome, EDF and CEA

103 The use of Large Eddy Simulation (see for instance [5] or [11]) for turbulence modelling was however 104 imposed for all contributions, following the results obtained from previous work on a simplified yet 105 representative configuration with one single rod inside one grid cell placed in a turbulent annular flow (see $106[6])$.

\section{$107 \quad 3.1 \quad$ Computational domain and boundary conditions}

108 The characteristics of the computational domains considered by Framatome, EDF and CEA respectively 109 are given in Figure 3.

\footnotetext{
${ }^{2}$ Star-CCM+® and any and all SIEMENS brand, product, service and feature names, logos and slogans are registered trademarks or trademarks of SIEMENS in the United States or other countries. All other brand, product, service and feature names or trademarks are the property of their respective owners
} 

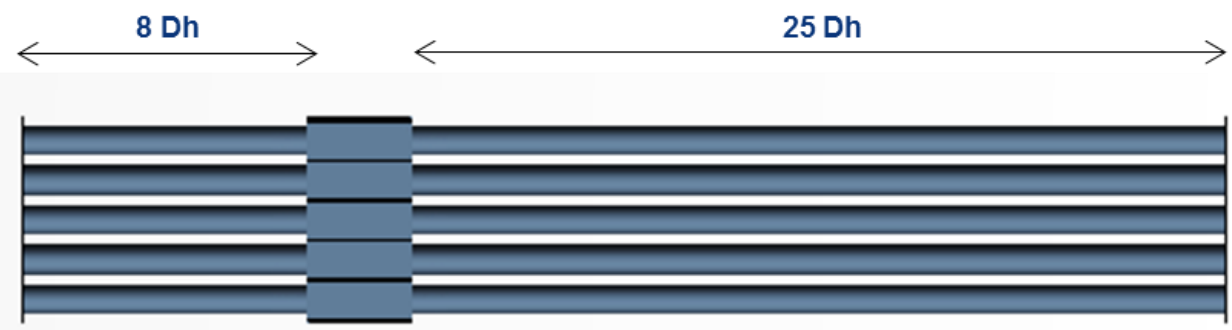

(a) Framatome computational domain, extending from $8 \mathrm{D}_{\mathrm{h}}$ upstream the mixing grid of interest to $25 \mathrm{D}_{\mathrm{h}}$ downstream, periodic boundary conditions are applied

(b) EDF computational domain, extending from $20 \mathrm{D}_{\mathrm{h}}$ upstream the mixing grid of interest to $20 \mathrm{D}_{\mathrm{h}}$ downstream,
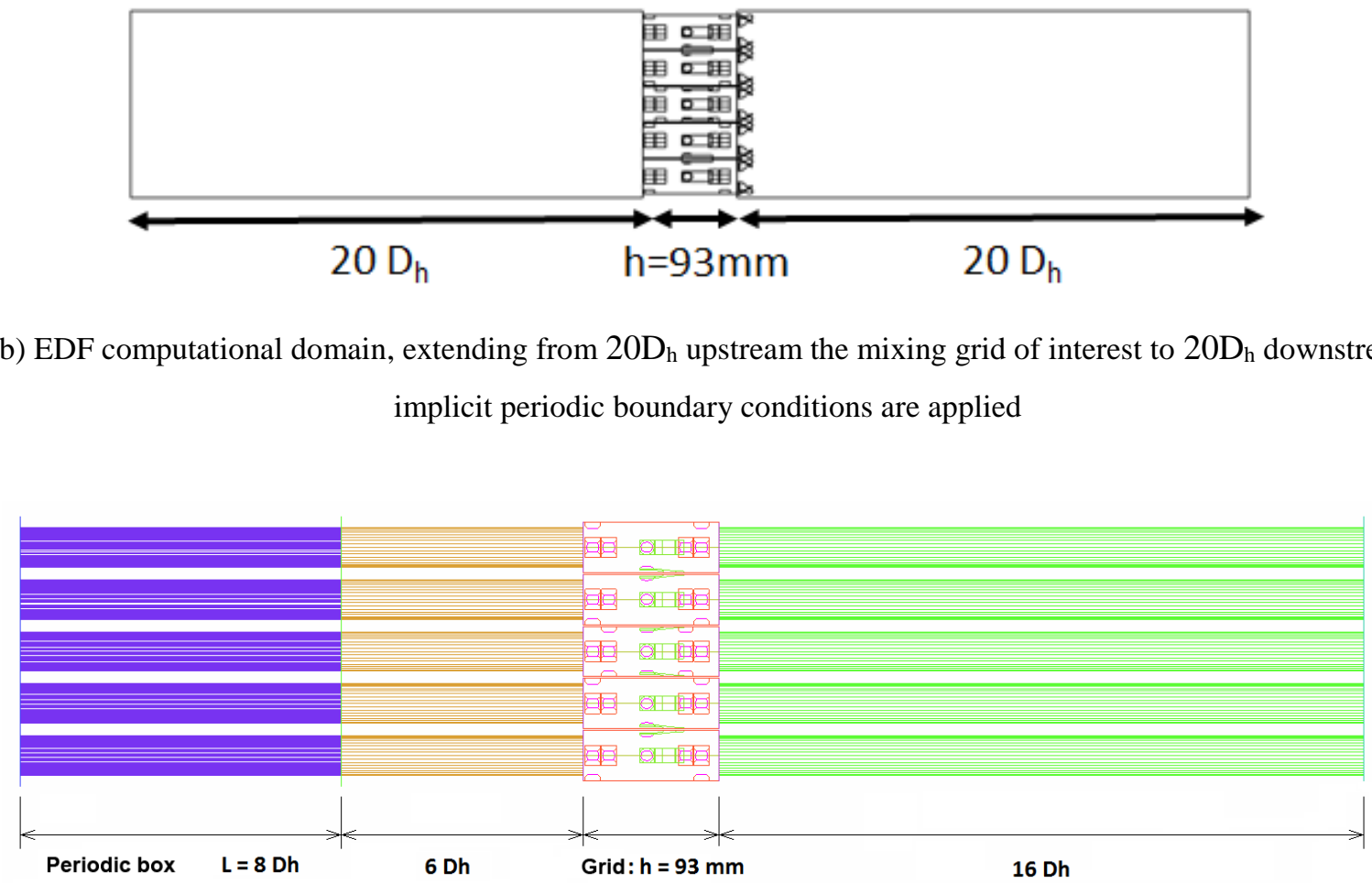

(c) CEA computational domain, extending from $6 \mathrm{D}_{\mathrm{h}}$ upstream the mixing grid of interest to $16 \mathrm{D}_{\mathrm{h}}$ downstream, and implementing a specific periodic box for turbulent inlet

123 For Framatome, the periodicity is achieved by mapping of the flow field (pressure and velocity) between

124 inlet and outlet to simulate periodic conditions. This mapping operation consists in extracting a set of data

125 from a given boundary surface (velocity or pressure field, for instance) in order to set it to another boundary.

126 This yields a three-phase calculation sequence:

127 - Phase 1: without any periodic condition, a constant velocity profile is set at the inlet and a constant 128 pressure profile is set at the outlet. This phase lasts 5 flow passes ; 
- Phase 2a: the mapped velocity is set at the inlet but the pressure boundary conditions remains unchanged. This phase lasts 5 flow passes;

- Phase 2b: the mapped pressure profile is set at the outlet. Both periodicity conditions are set. This phase lasts 5 flow passes;

- Phase 3: after solution stabilization of the first phases, data is collected after 15 flow passes.

134 For EDF, periodic conditions of translation are used in the stream-wise direction, with an imposed pressure 135 gradient calculated from the flow rate.

136 CEA suggests a different approach with the initialization of the turbulent velocity field at the bottom entry of the domain $\left(6 \mathrm{D}_{\mathrm{h}}\right.$ upstream of the grid) obtained through a so-called periodic recirculation box (beginning $8 \mathrm{D}_{\mathrm{h}}$ upstream of the bottom entry), where the bundle turbulence is fully established and from which the velocity conditions are extracted and imposed at each time step at the inlet of the physical domain. Pressure is imposed at the domain outlet.

141 In order to perform industrial and affordable computations, wall-modeled LES is used, especially by EDF 142 and CEA (see below for the particular case of Framatome). This approach might give correct mean values 143 (see Benhamadouche [13]). However, its use is still subject to discussion and objections (see Piomelli [14]) 144 and this approach using wall functions concepts can also be seen as a very first step of hybrid RANS/LES 145 technique (using a logarithmic profile for example). Table 2 describes the boundary conditions considered 146 along the walls.

\begin{tabular}{|c|c|}
\hline Framatome & EDF, CEA \\
\hline $\begin{array}{l}\text { So-called all- } y^{+} \text {approach from Star-CCM+, where } \\
\text { the viscous sublayer is fully resolved for low } \mathrm{y}^{+}(\mathrm{a} \\
\left.\text { standard wall law is applied for high } \mathrm{y}^{+}\right) \text {This } \\
\text { approach benefits from a specifically refined mesh } \\
\text { of the boundary layer along the internal walls (see } \\
\text { Paragraph } 2.2 \text { for meshing processes). }\end{array}$ & $\begin{array}{l}\text { A classical logarithmic wall function is used to } \\
\text { predict the wall shear stress and is active on each } \\
\text { wall computational cell : } \\
\qquad\left\{\begin{array}{c}\frac{U_{I}}{u^{*}}=\frac{1}{\kappa} \ln \left(y^{+}\right)+E \text { if } y^{+}>11.8 \\
\frac{U_{I}}{u^{*}}=y^{+} \text {otherwise }\end{array}\right. \\
\text { with } U_{I} \text { the tangential velocity, } y^{+}=\frac{\rho y u^{*}}{\mu} \text { the non- } \\
\text { dimensional distance to the wall, } \rho \text { the density and } \\
u^{*} \text { the friction velocity. } \\
\text { Solving for } u^{*} \text { yields the shear stress } \rho\left(u^{*}\right)^{2} .\end{array}$ \\
\hline
\end{tabular}




\subsection{Meshing processes}

150 The mesh used by Framatome for this simulation includes the following features.

- The cells used for meshing are trimmed, hexahedral cells, with local refinements especially around the grid surface.

159 The resulting mesh is composed of 35 million fluid cells.

160 Concerning EDF, the computational mesh (created with ICEM CFD v15.0, see Figure 4 (a) and (b) for some

161 details) is composed of 42 million hexahedra and fully conformal. Even if such a mesh is difficult to create 162 and time consuming, these mesh properties are extremely important, to not introduce numerical diffusion, 163 which is not suitable for LES. It was verified a posteriori that the logarithmic wall function is active almost 164 everywhere, except in some locations in the grid which complied with the wall-modeled LES carried out 165 (globally $\mathrm{y}^{+}>20$ ). The periodic top and bottom computational faces are also fully conformal. For more 166 details about the numerics and the results, see [15].

167 Finally, in the version used by CEA for the present work, TrioCFD requires a tetrahedral mesh, which has 168 the benefit of being easily generated in complex geometries such as the vicinity of the mixing grid of interest 169 (see again Figure 4 (c) and (d) for details of the mesh within the grid), but also comes with a number of 170 cells significantly higher than those proposed in the other simulation frameworks of the present paper (i. e. 171 around 200 million tetrahedral elements, for an equivalent global refinement level). The criterion expressed 172 in [7] of having 15 to 20 cells between two opposite walls is satisfied.

173 At this stage, no primastic layer can be implemented close to the walls with TrioCFD, yielding the need for 174 an active wall function almost everywhere in the model. 


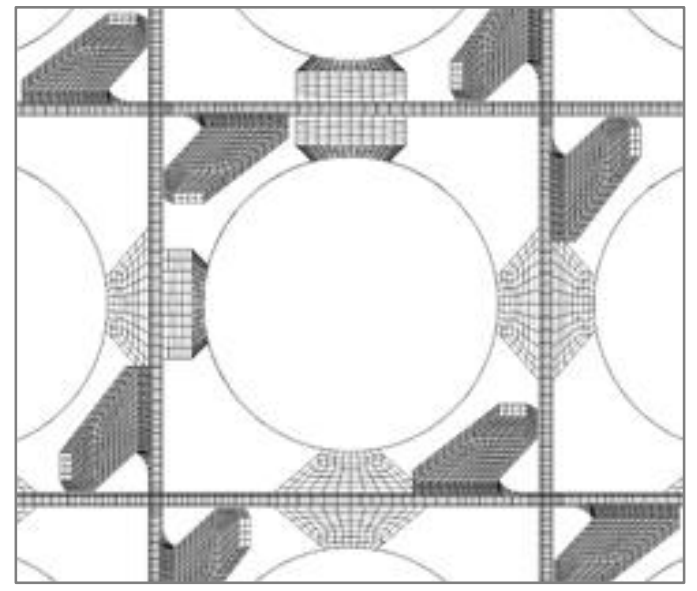

(a) EDF, Code_Saturne: mesh within the grid

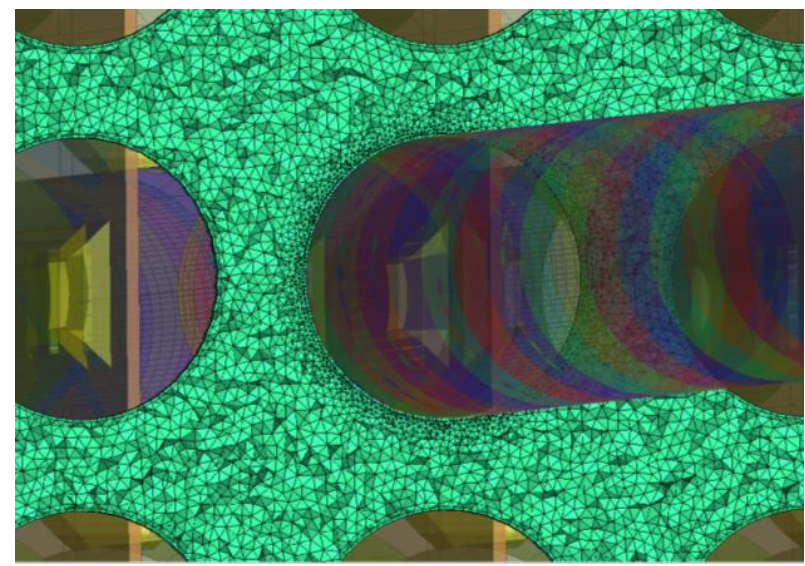

(c) CEA, TrioCFD: detail of the tetrahedral mesh within the bundle

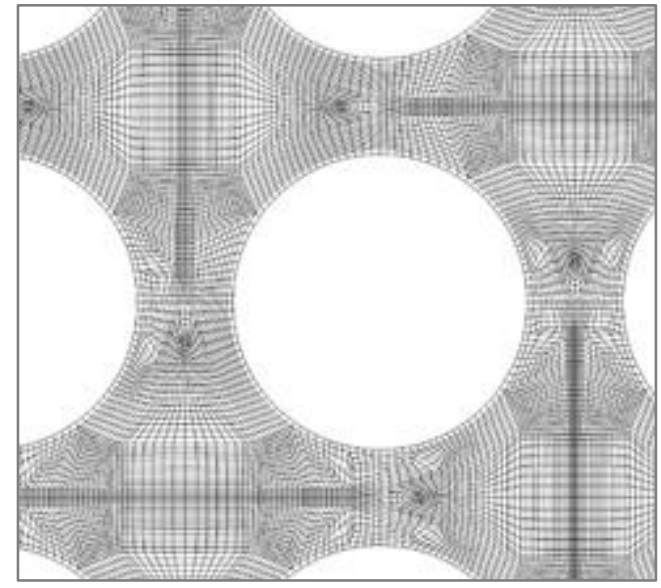

(b) EDF, Code_Saturne: mesh in the bare bundle region

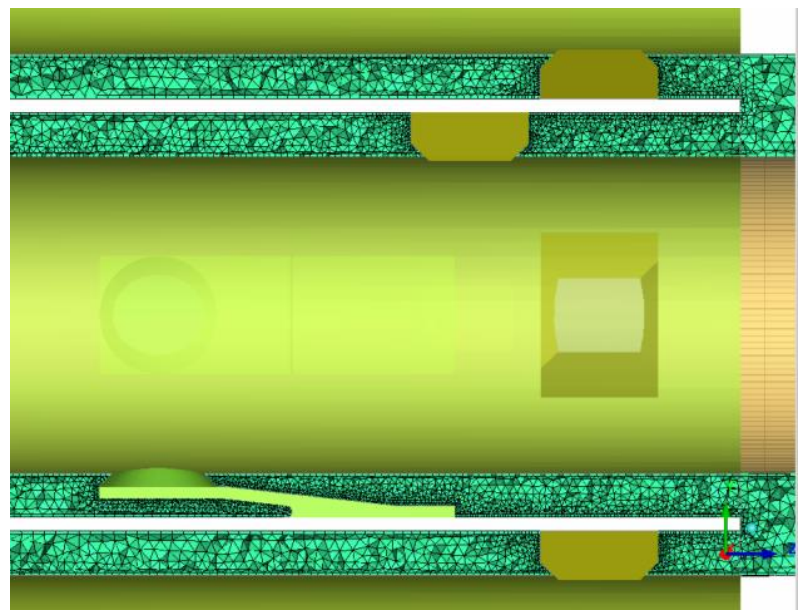

(d) CEA, TrioCFD: detail of the mesh in the vicinity of springs and dimples within the grid

\subsection{Turbulence modeling and numerical settings}

179 Framatome and EDF use the Smagorinsky subgrid-scale model [8] (in its standard version for Framatome

180 and its dynamic one for EDF) to model unresolved scales, whereas CEA uses the WALE (Wall-Adapting

181 Local Eddy-viscosity) model [9], designed to have a sub-grid scale viscosity with the right asymptotic

182 behavior in the near-wall region.

183 The main features of the various numerical methods are given in Table 3. 


\begin{tabular}{|c|c|c|}
\hline Framatome & EDF & CEA \\
\hline \multicolumn{3}{|l|}{ Spatial discretization } \\
\hline \multicolumn{2}{|c|}{$\begin{array}{l}\text { Finite volumes with cells of any shape (trimmed/hexa for Framatome and } \\
\text { hexa for EDF) }\end{array}$} & $\begin{array}{l}\text { Specific Finite Element/Finite } \\
\text { Volume for tetrahedral cells (P0/P1 } \\
\text { for pressure, P1NC for velocity) }\end{array}$ \\
\hline \multicolumn{3}{|c|}{ Numerical features for the unsteady solver } \\
\hline $\begin{array}{l}\text { Second order implicit temporal } \\
\text { discretization. }\end{array}$ & $\begin{array}{l}\text { Smagorinsky constant varying from } 0 \\
\text { to } 0.065 \\
\text { Velocity and pressure coupling } \\
\text { ensured via a predictor-corrector } \\
\text { algorithm with three outer sub- } \\
\text { iterations every time step } \\
\text { Centered time discretization (Crank- } \\
\text { Nicolson and Adams-Bashford) } \\
\text { Second order spatial discretization } \\
\text { with implicit gradient reconstruction } \\
\text { to take into account non orthogonal } \\
\text { faces } \\
\text { Centered convection scheme with } 2 \% \\
\text { of upwind in order to smooth pressure } \\
\text { and velocity oscillations in the } \\
\text { streamwise direction. }\end{array}$ & $\begin{array}{l}\text { Mixt } 2^{\text {nd }} \text { order (centered and } \\
2^{\text {nd }} \text { order Adams-Bashford explicit } \\
\text { time integration } \\
\text { second order for diffusion }\end{array}$ \\
\hline \multicolumn{3}{|c|}{ Time-step and stability (CFL condition) } \\
\hline $\begin{array}{l}\text { Constant time-step of } 5 \cdot 10^{-4} \mathrm{~s} \\
\text { Mean CFL about } 0.95\end{array}$ & $\begin{array}{l}\text { Constant time step equal to } 10^{-5} \mathrm{~s} \text {. } \\
\text { Mean CFL about } 0.94 \\
\text { Maximum CFL about } 2.25\end{array}$ & $\begin{array}{l}\text { Constant time-step equal to } 6.10^{-6} \mathrm{~s} \\
\text { Max CFL around } 0.8\end{array}$ \\
\hline \multicolumn{3}{|l|}{ Parallel solution } \\
\hline MPI & MPI \& OpenMP [10] & Flat MPI \\
\hline
\end{tabular}




\section{RESULTS AND CROSS-COMPARISONS WITH RESPECT TO EXPERIMENT}

189 Figure 5 shows instantaneous $2 \mathrm{D}$ velocity vectors obtained with the different solvers $1 \mathrm{D}_{\mathrm{h}}$ and $2 \mathrm{D}_{\mathrm{h}}$

190 downstream of the mixing vane grid. The secondary transverse flows show clearly that the mixing vane is

191 a split type one. The results are qualitatively in good agreement between the different models in terms of

192 both intensity and location of the generated flows.

193

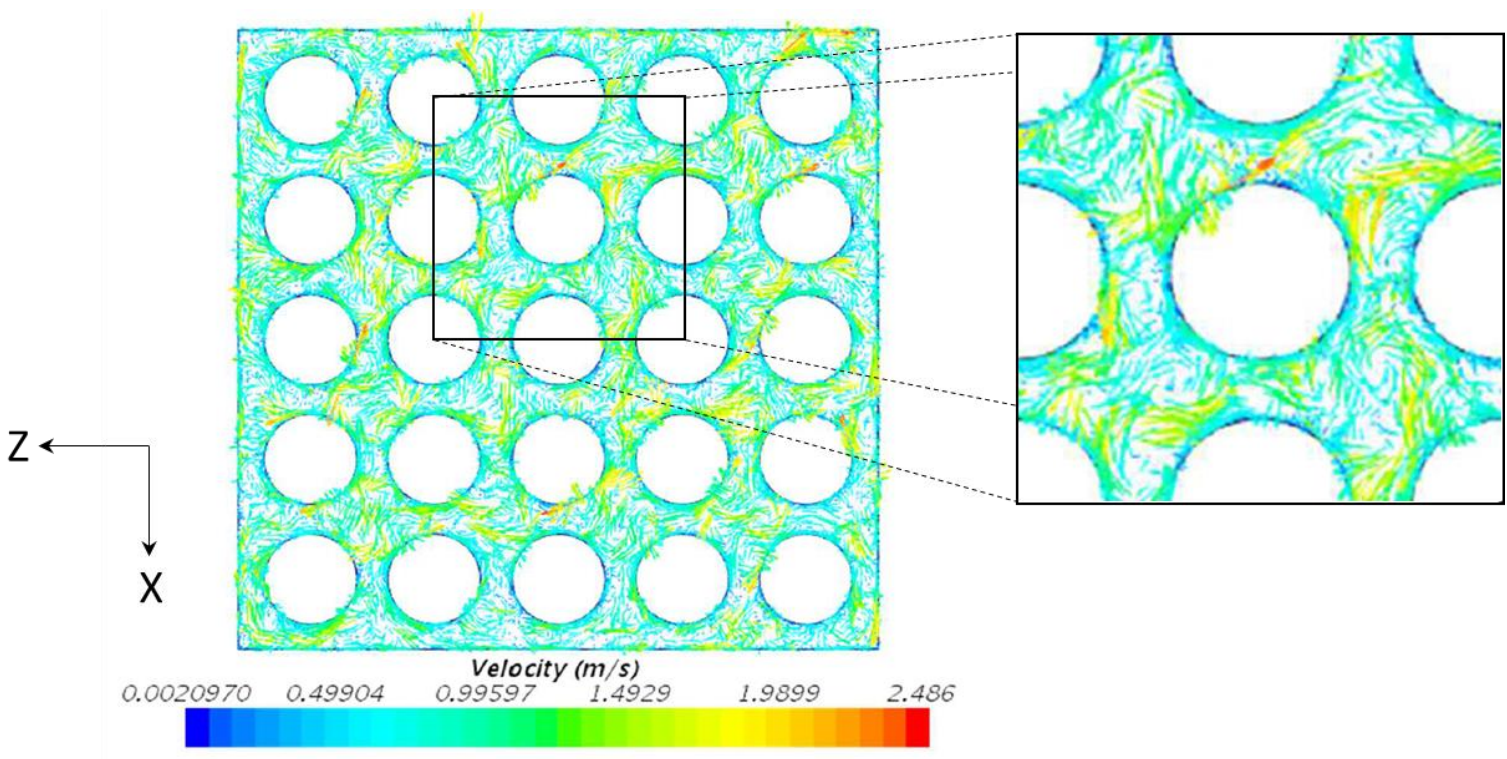

(a) Framatome, $1 \mathrm{D}_{\mathrm{h}}$ downstream of the grid

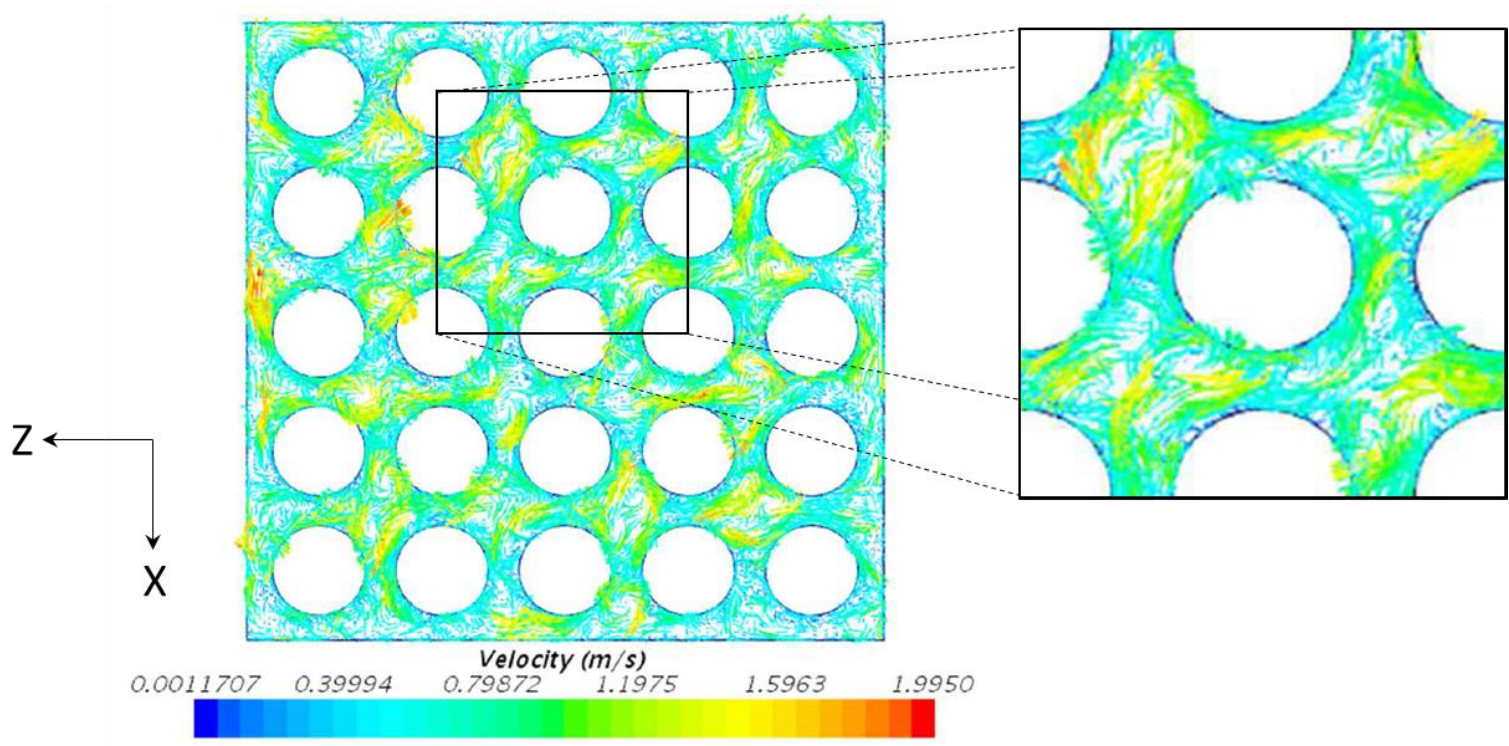

(b) Framatome, $2 \mathrm{D}_{\mathrm{h}}$ downstream of the grid 


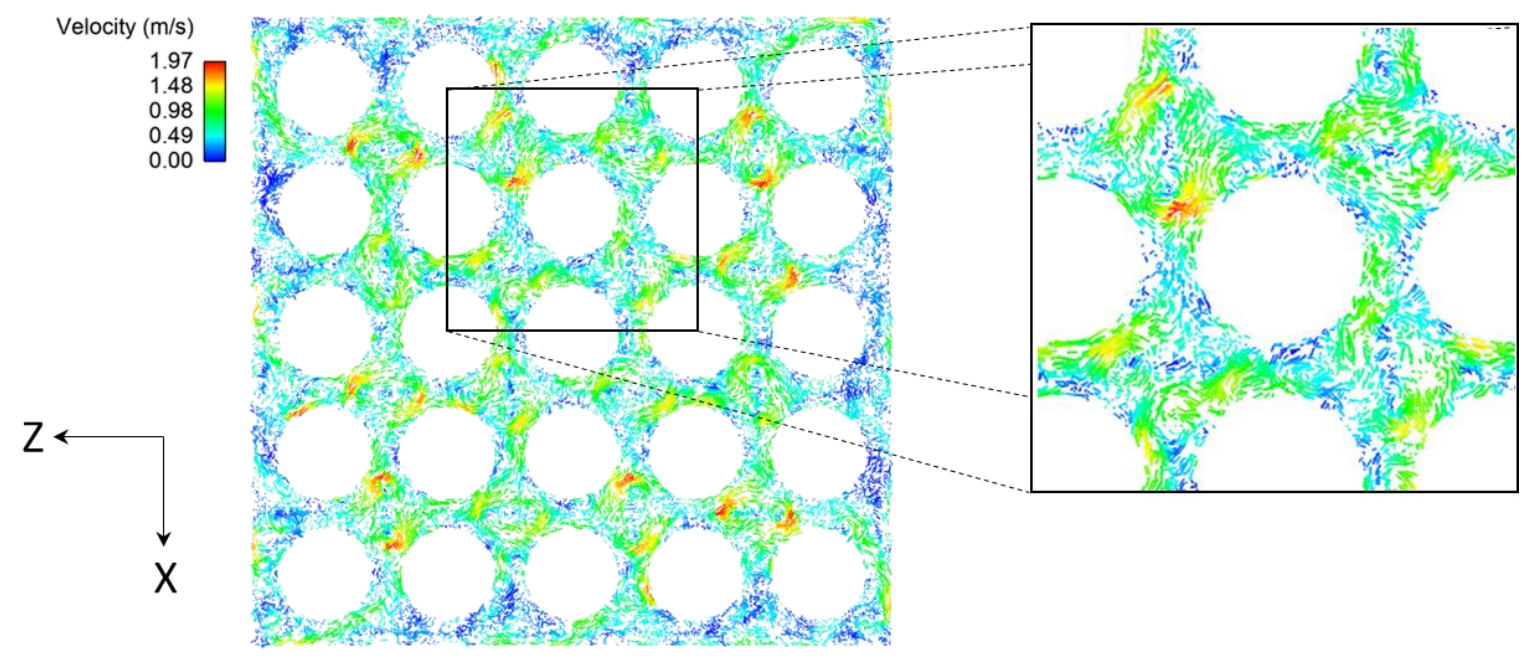

(c) EDF, $1 \mathrm{D}_{\mathrm{h}}$ downstream of the grid

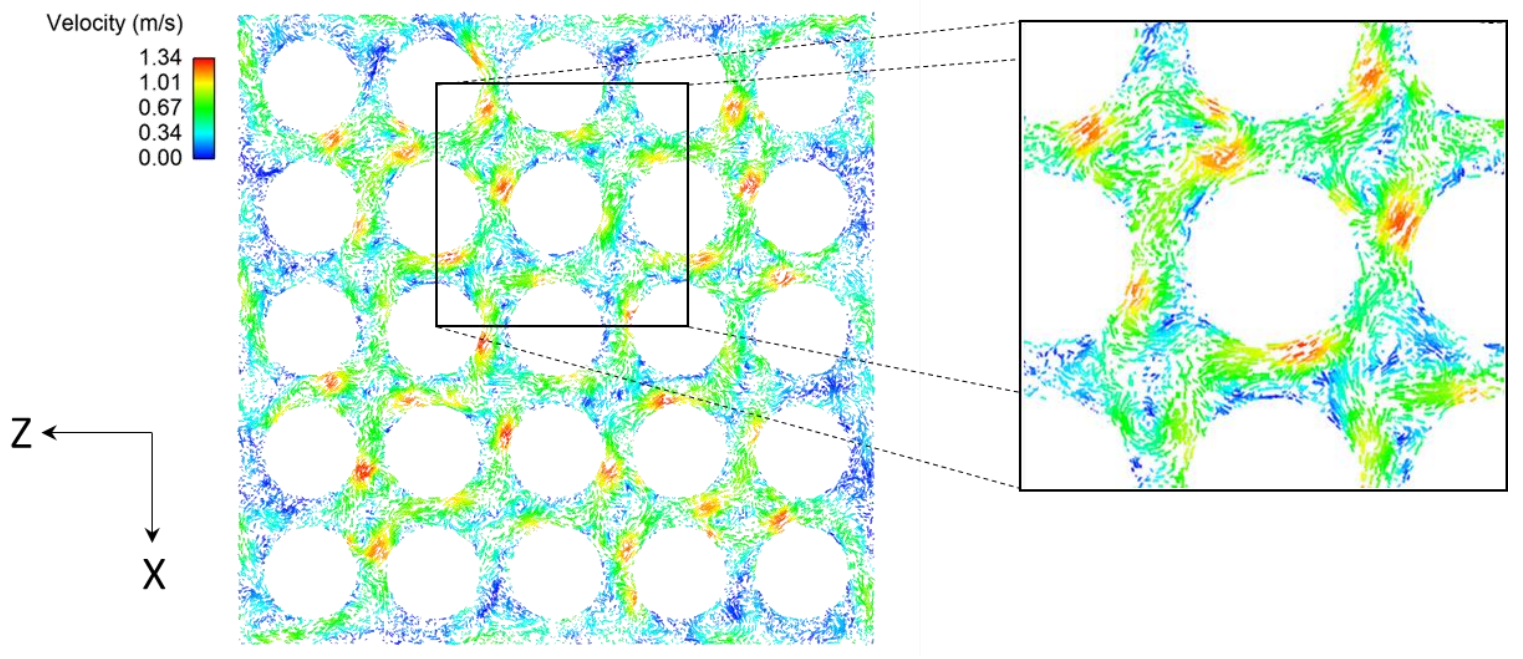

(d) EDF, 2 Dh downstream of the grid 


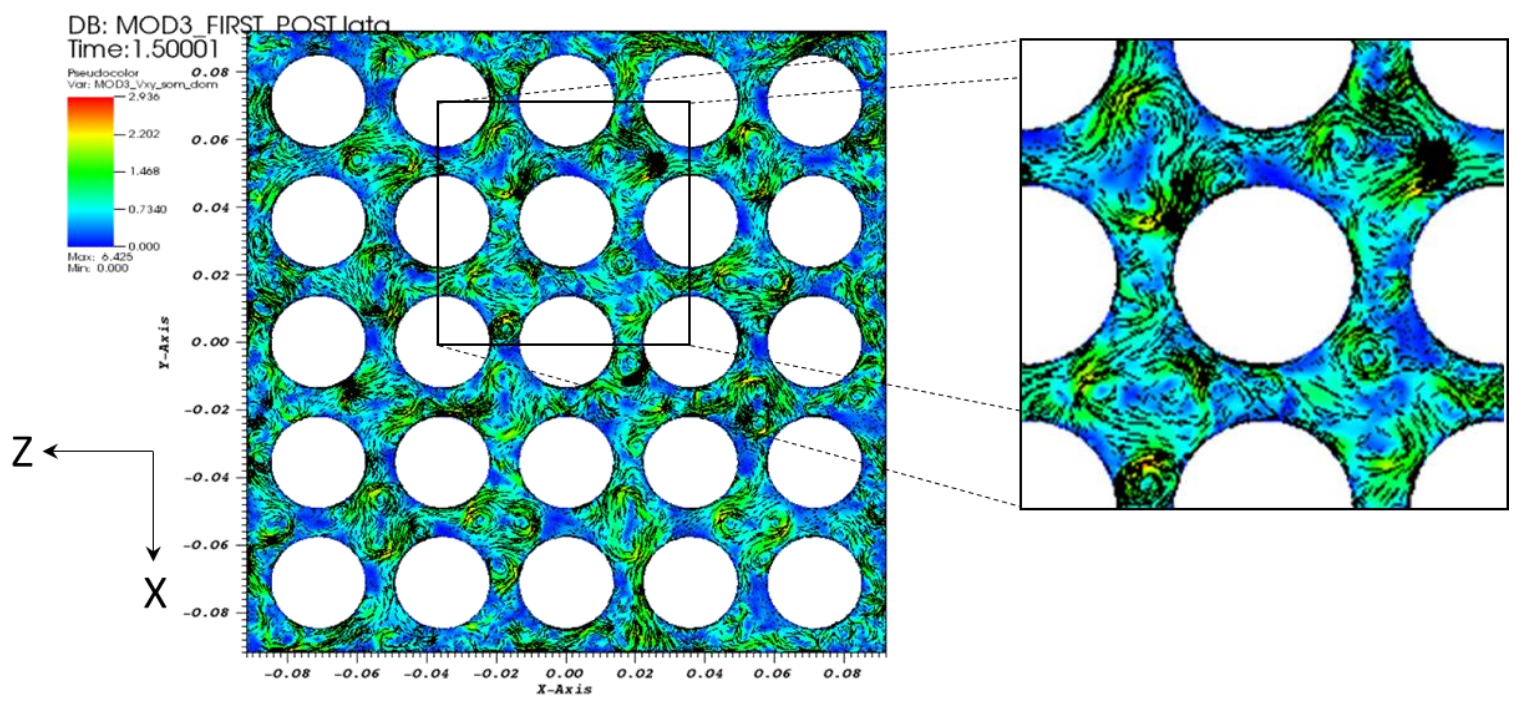

(e) CEA, $1 \mathrm{D}_{\mathrm{h}}$ downstream of the grid

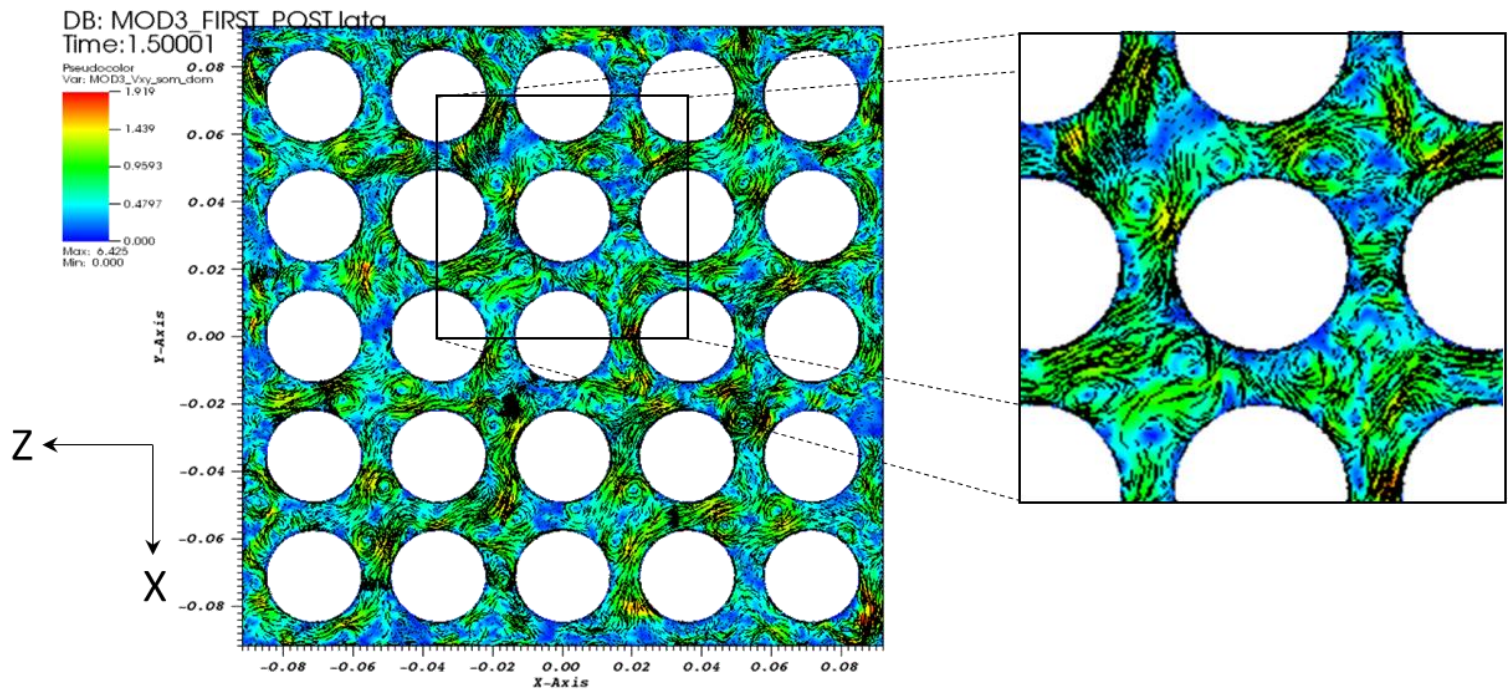

(f) CEA, $2 \mathrm{D}_{\mathrm{h}}$ downstream of the grid

194 Figure 5. Secondary transverse flow generated in the rod bundle downstream of the grid (colored by velocity in $\mathbf{m} / \mathbf{s}$ )

197 The next paragraphs focus on specifically measured quantities, to compare the three numerical solutions to 198 experimental measurements.

\section{$199 \quad 4.1 \quad$ Velocity profiles downstream of the mixing grid}

200 Vertical and cross velocities predicted by Star-CCM+, Code_Saturne and TrioCFD are plotted along line

201 T1 displayed on Figure 6. The numerical predictions compared to LDV data are shown in Figures 7 and 8 , 
202 at 2 and $5 \mathrm{D}_{\mathrm{h}}$ downstream of the mixing grid, respectively. The laser lights the window on the left. The 203 experimental profiles are only given for distances between 0 and $100 \mathrm{~mm}$ from sight window, due to 204 measurement difficulties further away from the window. The vertical lines correspond to the positions of 205 the rod symmetry axes.

206

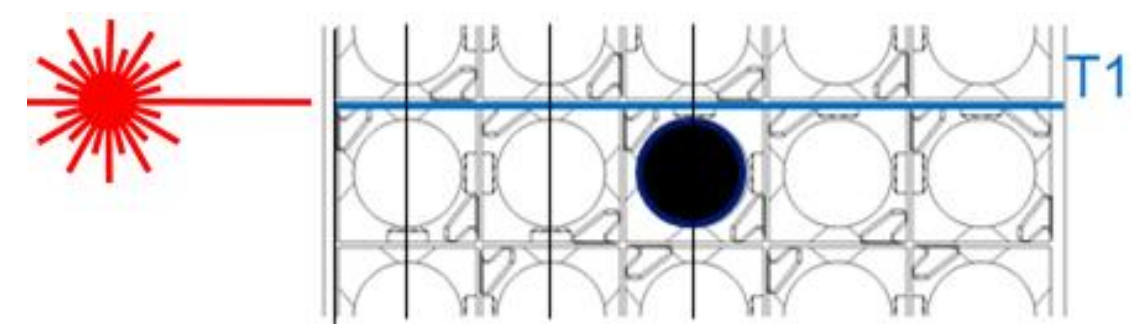

210 Whatever the CFD code used, the overall agreement between numerical and experimental data is very 211 satisfactory in the central region, for both components and both locations. Numerical results predicted by 212 TrioCFD and Star-CCM+ are closer to experimental vertical velocities, especially at $5 \mathrm{D}_{\mathrm{h}}$ for Star-CCM+, 213 whereas Code_Saturne is satisfactory at predicting the cross velocity. On the left side of the figures while 214 approaching the casing, differences of behavior can be observed between the three numerical predictions 215 and the experimental data due to the fact that the laser lights the window, which probably leads to distortion 216 of experimental measurements.

217 Concerning the cross velocity, it can clearly be observed a change of sign (between -0.5 and $0.5 \mathrm{~m} / \mathrm{s}$ ) at 2 $218 \mathrm{D}_{\mathrm{h}}$ from the grid, which indicates a very marked influence of mixing vanes near the grid, clearly predicted 219 by the three CFD codes and measured by LDV. Further downstream at $5 \mathrm{D}_{\mathrm{h}}$, the amplitudes of vertical and 220 cross velocity oscillations decrease: the influence of mixing vanes naturally decreases. The flow tends 221 toward a fully developed one in a bare bundle, after approximately 10 hydraulic diameters, although the 222 traces of the secondary vortices are still perceptible (not shown here). 


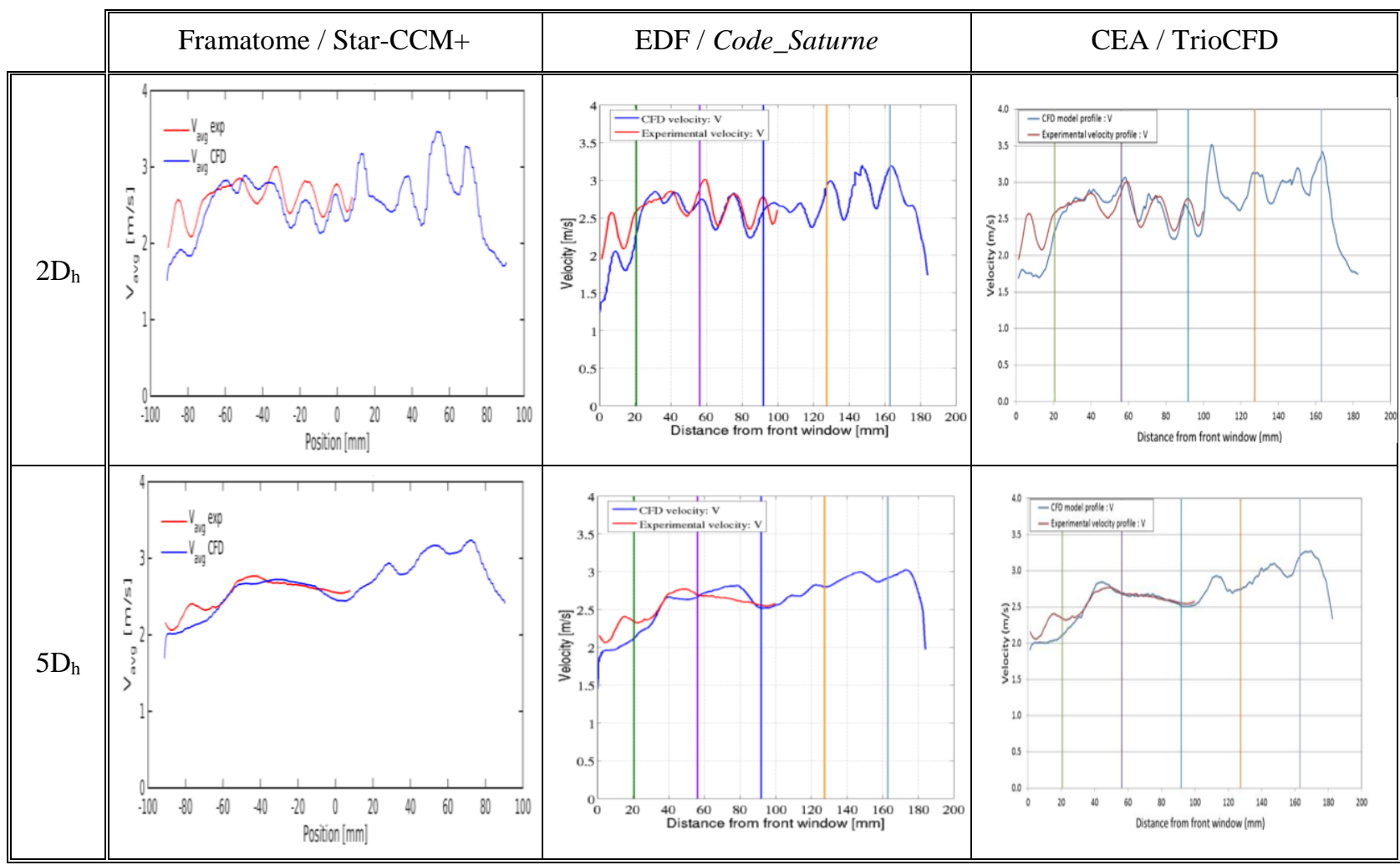

Figure 7. Vertical velocity profiles at 2 and $5 D_{h}$ along $T 1$ for the three CFD code (in blue CFD 


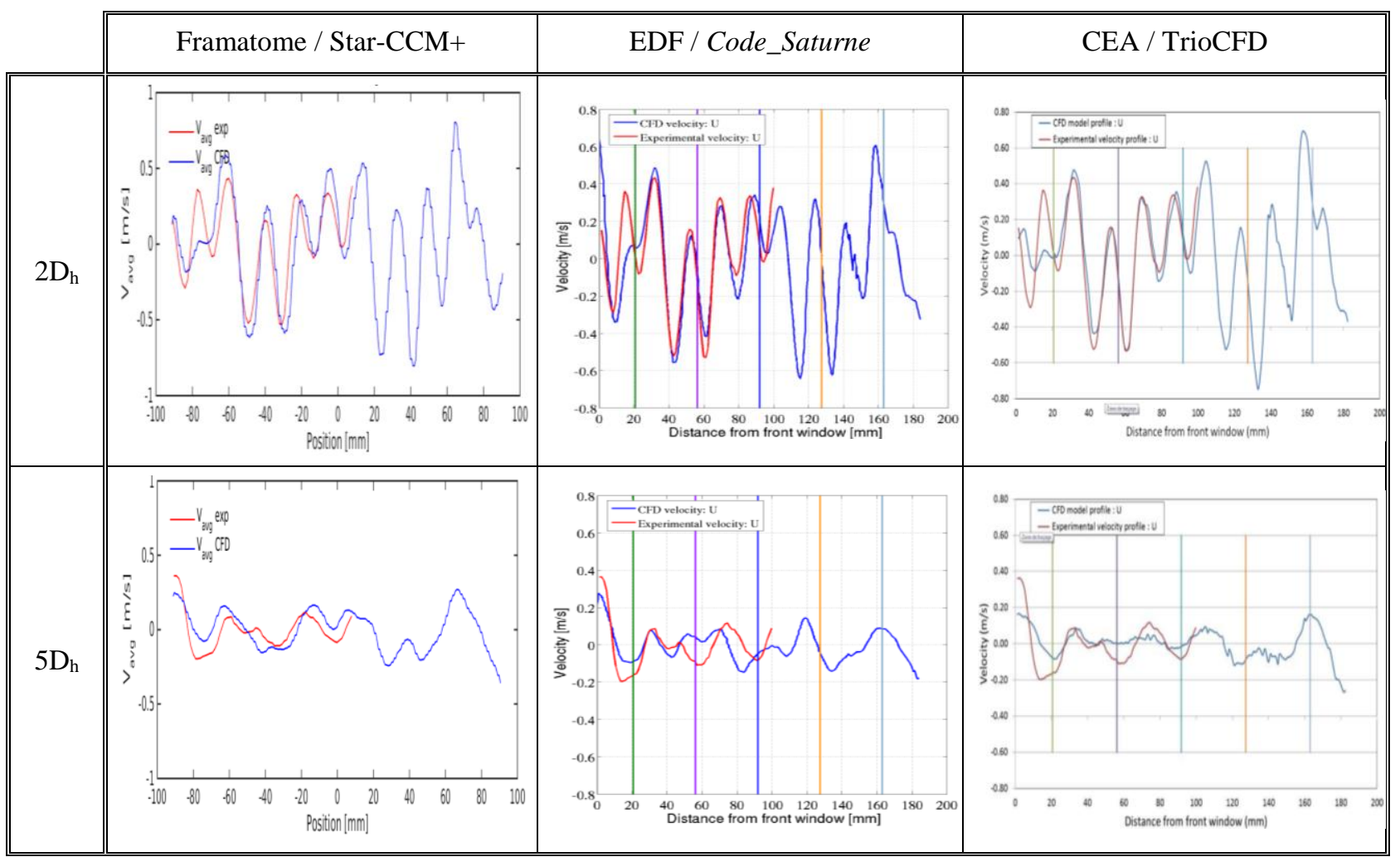

Figure 8. Cross velocity components profiles at 2 and $5 D_{h}$ along $T 1$, for the three CFD codes (in blue CFD velocity and in red experimental velocity).

\subsection{Pressure standard deviation distributions around the central rod}

235 As stated in Section 2 and shown in Figure 2 for reference experimental results, unsteady pressure 236 fluctuations measurements were performed around the central rod with a $10^{\circ}$ increment. All three 237 calculations were post-processed in order to compare the pressure standard deviation to experimental data 238 thanks to polar representation. The comparison is presented at altitudes of $1 \mathrm{D}_{\mathrm{h}}, 2 \mathrm{D}_{\mathrm{h}}, 5 \mathrm{D}_{\mathrm{h}}$ and $10 \mathrm{D}_{\mathrm{h}}$ 239 downstream of the mixing vane grid (see Figure 9). 


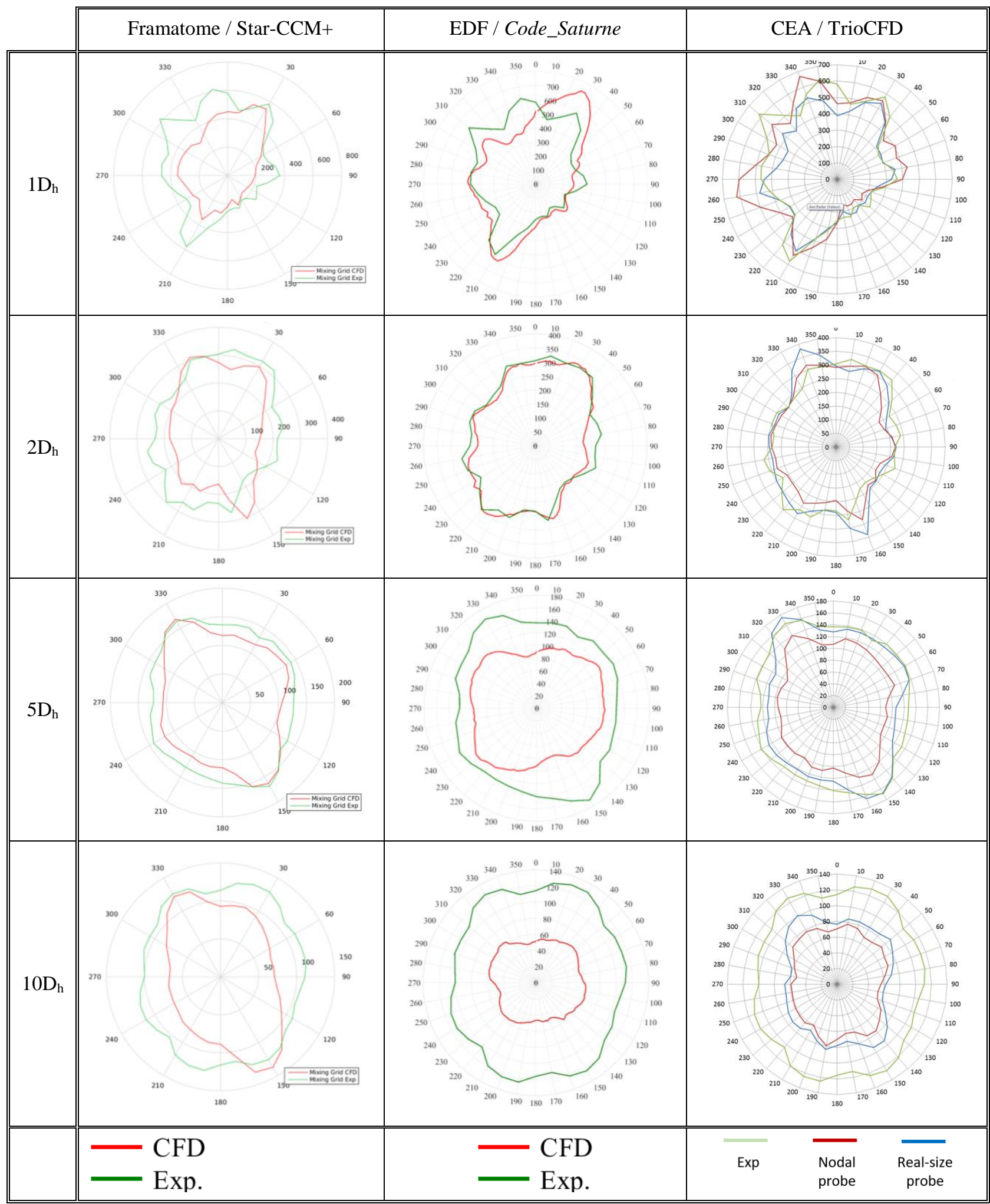

Figure 9. Polar representation of pressure standard deviation distribution around the central rod (red curves for CFD velocities, green curves for experimental velocities, blue curves do not have to 
245 For CEA, numerical results are provided for both nodal pressure probes and so-called real-size probes

246 where the pressure is integrated over a surface representing the actual size of the experimental sensor. Only

247 the results corresponding to nodal pressure probes, will be considered for the following. Real-size probes

248 unexpectedly yield more filtered results, which has to be investigated in further work.

249 Results are here discussed in terms of azimuthal accuracy. Predictably, the pressure standard deviation

250 azimuthal pattern is heavily polarized immediately after the mixing grid. This polarization is well

251 reproduced by the codes in its $\left(30^{\circ}-210^{\circ}\right)$ diagonal, one hydraulic diameter downstream of the grid. The

252 standard deviation pattern grows into a more homogeneous shape with altitude as well as it reduces in

253 amplitude as the flow tends towards a fully developed flow in a bare bundle. All the solvers start drifting

254 away from the experimental results at $5 \mathrm{D}_{\mathrm{h}}$, mostly in amplitude. Some $\left(150^{\circ}-330^{\circ}\right)$ polarization still

255 slightly persists at $5 \mathrm{D}_{\mathrm{h}}$ for Star-CCM+ and TrioCFD. This might be due to the use of wall functions for

256 TrioCFD or Code_Saturne. DNS or a wall-resolved LES in all programs would provide more elements to 257 conclude about this point.

$258 \quad$ 4.3 Pressure standard deviation decay with respect to the distance downstream of the 259 mixing grid

260 The decay of the pressure standard deviation around the central rod downstream of the mixing grid is plotted 261 in Figure 10. The slope in the vicinity of the grid (up to $3 \mathrm{D}_{\mathrm{h}}$ downstream), where the standard deviation 262 are the highest, is rather correctly reproduced by all the models. This is not the case going further away 263 from the grid: if the change of slope around $4 \mathrm{D}_{\mathrm{h}}$ seen in the experiment is reproduced by the three 264 simulations, the numerical results are inaccurate in all cases, yielding a decay after $5 \mathrm{D}_{\mathrm{h}}$ significantly faster 265 than the experimental measurement.

\section{DISCUSSION REGARDING LES VALIDATION AND RECOMMENDATIONS} FOR FUTURE WORK TO CONSOLIDATE THE PROPOSED RESULTS

269 The simulations proposed in the current paper represent a significant computational effort to provide and 270 compare best-estimate solutions in the CALIFS $5 \times 5$ configuration. Each proposed computational model, 271 including its own meshing process, software choice and solver parameters, comes with some particular 272 hypotheses clearly described in sections 3.1, 3.2 and 3.3. Models of this size are built in agreement with 273 known recommendations, especially as far as mesh refinement is concerned and systematic a posteriori 274 sensitivity and convergences studies are classically out of reach for simple reasons of requested 275 computational power and time. 
276 The first priority comment is that, whatever the mix of mesh characteristics and numerical solver, the 277 obtained results are closed to each other and to the experiments up to $4 \mathrm{Dh}$ downstream of the mixing grid.

278 This applies to the azimuthal polarization of the pressure fluctuations where they are the most significant, 279 the accurate reproduction of secondary cross flows in the tube bundle and the decay of the pressure standard 280 deviation. The second comment is that all computational models fail at reproducing the correct decay of the 281 pressure fluctuations after $5 \mathrm{Dh}$ downstream of the mixing grid.

282 While still not fully understood at this stage, this discrepancy in the agreement between experiment and 283 simulation seems to suggest that some persistent structures in the flow are missed in the numerical models, 284 which could be low frequency vortices generated by the vanes whose influence is masked by high 285 frequencies turbulent structures correctly captured just after the grid, or due to the use of wall functions 286 which filter the turbulence created by the walls.for Code_Saturne or TrioCFD

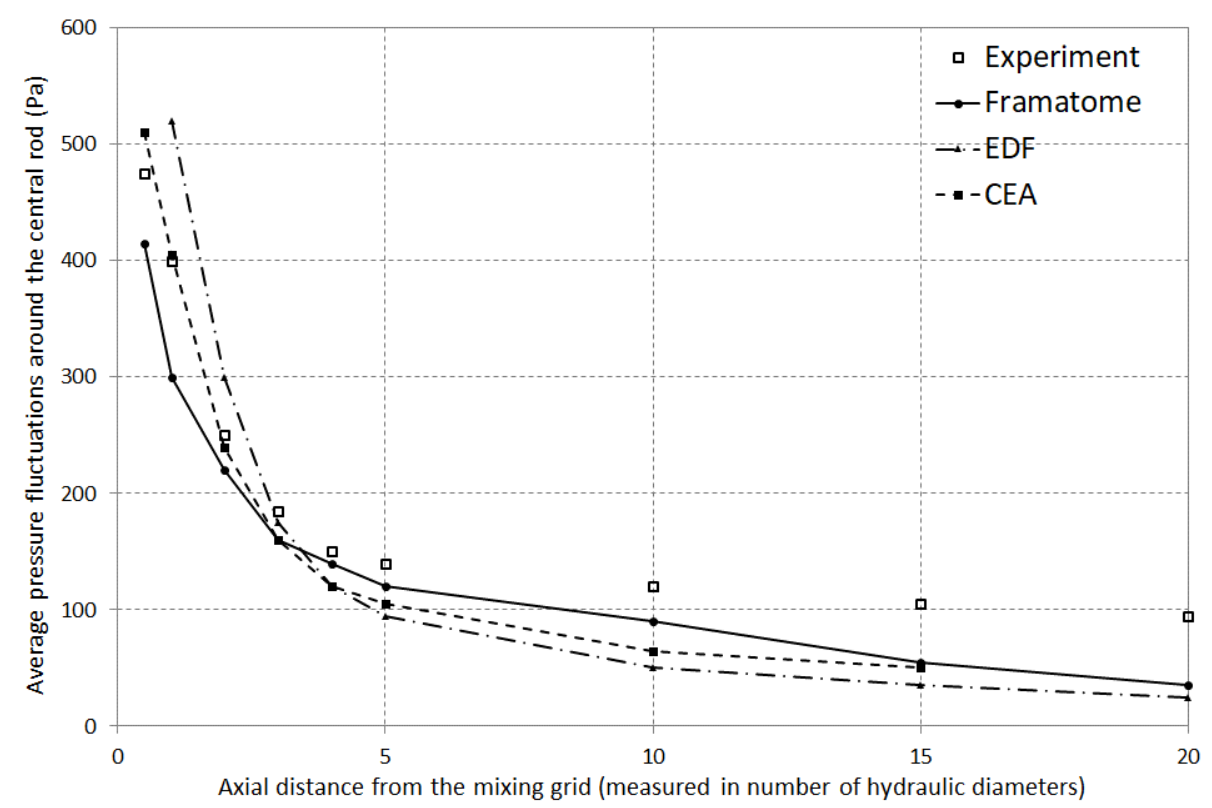

Figure 10. Pressure standard deviation decay downstream of the mixing grid

291 One strategy to address the remaining issue and go further the generally positive results obtained in the 292 proposed work would be to complement this study with sensitivity analyses to try to identify the modeling 293 components actually influencing the decay of the pressure fluctuations. The parameters to deal with could 294 principally be the mesh refinement, both in the wall normal direction and in the axial direction of the bundle, 295 and the models to account for the velocity profile in the boundary layer, up to a fully resolved and validated 296 solution close the walls to serve as a reference. This work should certainly be performed with less power 
consuming models, obtained for instance after a reduction of the Reynolds number, to allow the efficient

298 production of series of calculation in a reasonable time. It obviously implies that some new experimental

299 results are obtained at these lower Reynolds numbers and that discrepancies of the same nature are still

300 observed in these less challenging conditions. Advanced hybrid RANS/LES approaches, as introduced in

301 paragraph 3.1, should be worth testing in this prospective work, especially in the case where the fully

302 resolved velocity field close to the walls proves preponderant.

\section{$304 \quad 6$ CONCLUSION}

305 The proposed advanced benchmark involving three CFD software solutions provides significant insights 306 related to the maturity of CFD simulation for single phase highly turbulent flows in rod bundles equipped

307 with one or more mixing grid(s), representative of the need for fretting assessment in PWR reactor and 308 other design applications involving in-core hydraulics.

309 One major lesson is that very satisfactory results are globally obtained with all the models independently 310 from the modelling options introduced above, suggesting that the software offer for this kind of calculations 311 has reached a generic and significant level of robustness, accuracy and maturity. This comes with a 312 mandatory prerequisite that the suitable expertise is mobilized in model building and tuning of numerical 313 parameters associated to the chosen method for time and space discretization.

314 Some discrepancies yet remain regarding the reproduction of the pressure standard deviation decay far 315 downstream of the mixing in the present case. It opens research topics to identify the origin of these 316 differences between simulation and experiment, especially to state if they are likely to reappear in other 317 configurations with more significant effects, like for the complex hydraulic situation at the bottom of a 318 PWR fuel assembly, with incoming jets from the main water supply impacting the nozzle with consequences 319 on the turbulent flow through the bundle and the first holding grid above.

\section{References}

1. "Review of Fuel Failures in Water Cooled Reactors", IAEA Nuclear Energy Series NF-T-2.1 (2010).

2. M.P. Païdoussis, "A review of flow induced vibrations in reactors and reactor components. Nuclear Engineering 326 and design 74, 31-60 (1982).

327 3. F. Moreno, B. Collard, V. Faucher, "Measurement of fluctuating fluid pressure exerted on the walls of tube bundle". 328 Flow Induced Vibrations, The Hague, Netherlands, 2016. 

Measurements in 5x5 Rods Bundle Using Grids With and Without Mixing Vanes". 12th International Topical Meeting on Nuclear Reactor Thermal-Hydraulics, Operation and Safety, Qindao, China, 2018. 5. P. Sagaut, "Large Eddy Simulation for Incompressible Flows (Third ed.)”. Springer, 2006. 6. S. Delafontaine, "Simulation of unsteady fluid forces on a single rod downstream of mixing grid cell". Nuclear Engineering and Design, vol. 332, 2018.

335 7. Best practice Guidelines for the use of CFD in Nuclear Reactor Safety Application, Collective document, 2007, 336 OECD Nuclear Energy Agency, Committee on the Safety of Nuclear Installations, NEA/CSNI/R-2007-5.

337 8. M. Germano, U. Piomelli, P. Moin, W. Cabot, "A dynamic subgrid-scale eddy viscosity model”, Physics of Fluids, vol. 3(7), 1991.

9. F. Ducros, F. Nicoud, "Subgrid-scale stress modelling based on the square of the velocity gradient tensor". Flow Turbulence and Combustion, vol. 62(3), 1999.

342 computations on Petascale systems". Computers \& Fluids, vol. 3(7), 2011.

343 11. Benhamadouche, S., Moussou, P., Le-Maître, C., 2009. CFD estimation of the flow-induced vibrations of a fuel 344 rod downstream a mixing grid. Proceedings of PVP 2009 ASME Pressure Vessels and Piping 2009 / Creep 8 345 Conference, July 22-26, Prague, Czech Republic.

346 12. D. Wells and Y. Hassan, "Overview of CFD Round Robin Benchmark of the High Fidelity Fuel Rod Bundle 347 NESTOR Experimental Data", The $16^{\text {th }}$ International Topical Meeting on Nuclear Reactor Thermal Hydraulics 348 (NURETH-16) , Hyatt Regency Chicago, Chicago, IL, USA, August 30-September 4 (2015).

349 13. S. Benhamadouche. On the use of (U)RANS and LES approaches for turbulent incompressible single phase flows 350 in nuclear engineering applications. Nuclear Engineering and Design, 312, pp. 2-11 (2017) 14. Piomelli, U., 2008. Wall-Layer Models for Large-Eddy Simulations. Progress in Aerospace Sciences, Large Eddy Simulation - Current Capabilities and Areas of Needed Research, 44, no. $6: 437-46$. 15. Benhamadouche, S., Gauffre, M.-C., Badel, P. Wall-modelled large eddy simulation of the flow through PWR fuel 354 assemblies AT $\mathrm{ReH}=66,000$ - Validation on califs experimental setup, International Topical Meeting on Advances in Thermal Hydraulics, ATH 2018 - Embedded Topical Meeting pp. 765-776, 2018. 16. U. Bieder, F. Falk, G. Fauchet, Les analysis of the flow in a simplified pwr assembly with mixing grid, Progress 357 in Nuclear Energy 75 (2014) $15-24$.

358 17. G. Chen, Z. Zhang, Z. Tian, X. Dong, Y. Wang, Cfd simulation for the optimal design and utilization of experiment to research the flow process in pwr, Annals of Nuclear Energy 94 (2016) 1 - 9.

360 18. J. Xiong, R. Cheng, C. Lu, X. Chai, X. Liu, X. Cheng, Cfd simulation of swirling flow induced by twist vanes in 361 a rod bundle, Nuclear Engineering and Design 338 (2018) $52-62$.

362 19. U. Bieder, F. Falk, G. Fauchet, Cfd analysis of the flow in the near wake of a generic pwr mixing grid, Annals of 363 Nuclear Energy 82 (2015) $169-178$.

364 20. Z. Karoutas, C. Gu, B. Scholin, 3-d flow analyses for design of nuclear fuel spacer, Proceedings of the Seventh 365 International Meeting on Nuclear Reactor Thermal-Hydraulics (1995) 3153-3174. 
366 21. W.-K. In, D.-S. Oh, T.-H. Chun, Flow analysis for optimum design of mixing vane in a pwr fuel assembly, Nuclear 367 Engineering and Technology 33 (2001).

368 22. S. Cheng, H. Chen, X. Zhang, Cfd analysis of flow field in a $5 \times 5$ rod bundle with multi-grid, Annals of Nuclear 369 Energy 99 (2017) $464-470$.

370 23. J. R. Lee, J. Kim, C.-H. Song, Synthesis of the turbulent mixing in a rod bundle with vaned spacer grids based on 371 the oecd-kaeri cfd benchmark exercise, Nuclear Engineering and Design 279 (2014) 3 - 18. 